\title{
Novel therapy for locally advanced triple-negative breast cancer
}

\author{
ATSUKO YAMADA $^{1}$, SHINJI OSADA ${ }^{2}$, TOSHIYUKI TANAHASHI ${ }^{1}$, SATOSHI MATSUI $^{2}$, \\ YOSHIYUKI SASAKI ${ }^{1}$, YOSHIHIRO TANAKA ${ }^{1}$, NAOKI OKUMURA ${ }^{1}$, NOBUHISA MATSUHASHI ${ }^{1}$, \\ TAKAO TAKAHASHI ${ }^{1}$, KAZUYA YAMAGUCHI ${ }^{1}$ and KAZUHIRO YOSHIDA ${ }^{1}$ \\ ${ }^{1}$ Department of Surgical Oncology, ${ }^{2}$ Multidisciplinary Therapy for Hepato-Biliary-Pancreatic Cancer, \\ Gifu University Graduate School of Medicine, Gifu, Japan
}

Received May 29, 2015; Accepted July 9, 2015

DOI: $10.3892 /$ ijo.2015.3113

\begin{abstract}
To evaluate a novel therapy for triple-negative breast cancer (TNBC), the biological responses to vitamin K3 (VK3) should be considered with the understanding of the features of breast cancer. In human breast cancer cell lines, the effects of VK3 on cell growth inhibition and the cellular signaling pathway were determined by MTT assay and western blotting. In the in vivo study, a subcutaneous tumor model of breast cancer was created, VK3 was injected into the subcutaneous tumors, and tumor size was measured. The $\mathrm{IC}_{50}$ of $\mathrm{VK} 3$ for breast cancer cells was calculated to be 11.3-25.1 $\mu \mathrm{M}$. VK3 induced phosphorylation of whole tyrosine and epidermal growth factor receptor. VK3 mediated phosphorylation of extracellular signal-regulated kinase (ERK) and c-Jun NH2-terminal kinase (JNK) for $30 \mathrm{~min}$. ERK but not JNK phosphorylation was maintained for at least $6 \mathrm{~h}$. In contrast, another antioxidant agent, catalase, showed no effect on either ERK phosphorylation or growth inhibition. On built-up tumors under the skin of mice, local treatment with VK3 was effective in a time- and dose-dependent manner, and the experiments for total tumor volume also showed a dose-dependent effect of VK3. The expression of phosphorylated ERK was clearly detected at 10.9 times the control in tumor tissue, whereas ethanol itself showed no effect. In conclusion, ERK plays a critical role in VK3-induced growth inhibition, and it will be the focus of next steps in the development of molecular therapy for $\mathrm{TNBC}$.
\end{abstract}

\section{Introduction}

Breast cancer remains the most frequent tumor and the leading cause of cancer-related deaths among the female population worldwide (1). Breast cancers are classified on the basis of three protein expression markers: estrogen receptor (ER), progesterone receptor $(\mathrm{PgR})$, and human epidermal growth factor

Correspondence to: Dr Shinji Osada, Multidisciplinary Therapy for Hepato-Biliary-Pancreatic Cancer, Gifu University Graduate School of Medicine, 1-1 Yanagido, Gifu 501-1194, Japan

E-mail: sting@gifu-u.ac.jp

Key words: vitamin K3 (menadione), triple-negative breast cancer, ablation therapy, minimally invasive therapy receptor 2 (HER2). In the standard chemotherapies, therefore, agents targeting anti-hormone, anti-HER2 or other expression of various receptors have been selected $(2,3)$. Hormonal therapies can be effective in treating tumors that express the hormone receptors ER or PgR (2), and HER2-directed therapies are useful for tumors that express HER2 (4). However, the treatment options for triple-negative breast cancers (TNBC), which do not express ER, PgR or HER2 and are detected in $15 \%$ of breast cancers (5), are restricted to chemotherapy, even for radiation and surgery (6). Actually, only a limited number of effective treatments are available to patients with advancedstage TNBC (7), and prognosis in patients with TNBC is much worse than that in patients with non-TNBC. For example, the 3 -year disease-free rate after certain therapy in patients with TNBC was $63 \%$, significantly lower than the $76 \%$ in those with non-TNBC (8). Recent studies have identified molecular subtypes in TNBC from the understanding of biologic heterogeneity that are leading to additional potential therapeutic targets for evaluation (9). However, in this era of personalized medicine (10), there have been no trials of targeted agents demonstrating significant benefit for patients with any subtype of TNBC (11). Local treatment has been the focus recently as a next step in obtaining further favorable treatments for TNBC. Indeed, ablation therapy with radiofrequency energy $(12)$ or cryotherapy $(13,14)$ is an emerging minimally invasive therapy for small and localized breast cancers. However, the rate of overall local response is still low, at $48 \%$ even when combined with liposomal doxorubicin for unresectable chest wall recurrences of breast cancer (15). Further, problematic complications of skin fibrosis after radiofrequency ablation continue to occur (6), indicating the difficulty in selecting a satisfactory device.

Menadione (vitamin K3: VK3) is chemically synthesized to have anticancer effects against various cancers $(16,17)$, but its mechanism remains unclear. In vivo studies revealed that menadione acts as a strong chemo-sensitizer when administered in combination with various conventional chemotherapeutic agents in different cancer models (18), and it is active against doxorubicin-resistant leukemia cells in rats (19). On squamous cells, VK3 was found to have limited cytotoxic effects on malignant cells, but not normal tissue, from the observation in which the half maximal inhibitory concentration $\left(\mathrm{IC}_{50}\right)$ for cancer and normal cells was 8.45 and $98.5 \mu \mathrm{M}$, respectively (18). In several trials of modulated chemotherapy, VK3 has 
so far been combined with the alkylating agent mitomycin $\mathrm{C}$ (20-22). According to the clinical results of 23 patients with advanced lung cancer, serious complications over grade 3 , such as hematologic toxicity or pneumonia, were detected in $31 \%$, despite an objective response rate of just $9 \%$ (21). In addition, in 43 cases of gastrointestinal cancer, $27 \%$ of patients had side effects over grade 3 , such as hemolytic anemia or uremic syndrome, without any objective responses (22). Because of its strong toxicity, VK3 has been shown to cause a variety of side effects when administered systemically. However, local treatment is still expected to lead to satisfactory outcomes for body surface-type cancers such as breast cancer, even for TNBC. To evaluate the significance of this novel treatment concept, the biological responses induced by VK3 should be considered with the understanding of the features of breast cancer. Therefore, in the present study, the development of ablation therapy combined with VK3 will be estimated from not only observation of the mechanism but also by specific factors to predict the anti-tumor effect of this therapy.

\section{Materials and methods}

Cell lines and culture conditions. Cells from the MCF-7, SK-BR3, BT474 and MDA-MB-231 human breast carcinoma cell lines were obtained from the American Type Culture Collection (ATCC, Manassas, VA, USA). Cell were cultured in DMEM medium (Wako, Osaka, Japan) supplemented with $10 \%$ heat-inactivated fetal bovine serum (FBS), $4 \mathrm{mM}$ nonessencial amino acid (NEAA), $4 \mathrm{mM}$ L-glutamine and $1 \%$ penicillin-streptomycin-amphotericin solution (all from SigmaAldrich, St. Louis, MO, USA) in a humidified atmosphere of $5 \% \mathrm{CO}_{2} / 95 \%$ air at $37^{\circ} \mathrm{C}$. Cells were passaged once a week.

Cell proliferation assay. Cell growth was assessed by a standard 3-(4, 5-dimethyl-thiazol-2-yl)-2,5-dephenyltetrazolium bromide (MTT) assay $(23,24)$, which detects the dehydrogenase activity in viable cells. A total of $1 \times 10^{4}$ MDA-MB-231 cells were seeded into each of the 96-well culture plates overnight and kept in a humidified atmosphere of $5 \% \mathrm{CO}_{2}$ and $95 \%$ air at $37^{\circ} \mathrm{C}$. After $24-\mathrm{h}$ incubation, diluted menadione (5-100 $\mu \mathrm{M})$ was added to each well of the culture medium. After 24, 48 and $72 \mathrm{~h}$, the culture medium was removed, and $100 \mu \mathrm{l}$ of a $0.5-\mathrm{mg} / \mathrm{ml}$ solution of MTT (Sigma-Aldrich) was added to each well. The plates were then incuvated for $4 \mathrm{~h}$ at $37^{\circ} \mathrm{C}$. The culture medium was replaced with $100 \mu \mathrm{l}$ of dymethyl sulfoxide (Wako) per well, and the absorbance at the 540-nm wavelength was measured using a 2104 EnVision Multilabel Reader (Perkin-Elmer, Waltham, MA, USA).

Detection of reactive oxygen species (ROS). We used the Total ROS detection $\mathrm{kit}^{\circledR}$ to detect intracellular ROS. A total of $6 \times 10^{5}$ MDA-MB-231 cells were seeded into each of the 6-well culture plates overnight and kept in a humidified atmosphere of $5 \% \mathrm{CO}_{2}$ and $95 \%$ air at $37^{\circ} \mathrm{C}$. After $24-\mathrm{h}$ incubation, the cells were simultaneously treated with an experimental test agent (or control) and loaded with the same volume of the ROS detection solution. The ROS detection mix was carefully removed from the glass slides by gently tapping against layers of paper towel, or from the tissue culture plates The cells were washed cells twice with $1 \mathrm{X}$ wash buffer, adding a few drops of 1X wash buffer, and immediately overlayed with a cover slip and observed under a fluorescence/confocal microscope using standard excitation/emission filter sets. Oxidative stress detection requires a filter set compatible with fluorescein (Ex/ Em: 490/525 nm).

Western blot analysis and antibodies. Treatment of the specimen was as described previously (25-27). The cell lysate was boiled in sample buffer solution (Wako). Total cell protein extracts $(20 \mu \mathrm{g} /$ lane $)$ were separated by sodium dodecylsulface-polyacrylamide gel electrophoresis using SuperSep ${ }^{\mathrm{TM}}$ (Wako) and were electrophoretically transfected onto polyvinyl difluoride menmbranes. The membranes were blocked with PVDF blocking reagent (Toyobo, Osaka, Japan) for $1 \mathrm{~h}$. The membrane was then incubated with primary antibodies against $\beta$-actin, phosphorylated type of extracellular signalregulated kinase (p-ERK), c-jun N-terminal kinase (p-JNK), p-AKT, mammalian target of rapamycin (p-mTOR), hepatocyte growth factor receptor (p-cMet), epithelial growth factor receptor (p-EGFR) and caspase-3 (1:5,000; Cell Signaling Technology, Danvers, MA, USA) and EGFR inhibitor (1:5,000; Calbiochem 324674, Merck KGaA, Germany) overnight at $4^{\circ} \mathrm{C}$. The primary antibodies were diluted with Can Get Signal Solution 1 (Toyobo). The membrane were then washed with Dako washing buffer (Dako, Glostrup, Denmark) and incubated with the appropriate secondary antibodies (1:25,000; Millipore, Darmstadt, Germany), which were diluted with Can Get Signal Solution 2. The immunoreactive proteins were visualized by chemiluminescence using a LAS-4000 (Fuji film, Tokyo, Japan) and analyzed using ImageJ software (NIH, Bethesda, MD, USA).

Animals and in vivo experiments. Female 5-week-old $\mathrm{BALB} / \mathrm{c}$ nu/nu mice were purchased from SRL (Hamamatsu, Japan) and housed in the animal facilities of the Division of Animal Experiment, Life Science Research Center, Gifu University (Gifu, Japan) with free access to water and food. A subcutaneous tumor model of breast cancer was created by injection of $2.0 \times 10^{7} \mathrm{MDA}-\mathrm{MB}-231$ cells into the back of nude mice as described previously (28). At 21 days after injection, menadione was injected into subcutaneous tumors and the tumor size was measured each day. After 3-4 weeks, the subcutaneous xenografts were injected with PBS, ethanol or menadione, removed and evaluated by western blot analysis in an immunohistochemical study. Animal experiments in this study were performed in compliance with the guidelines of the Institute for Laboratory Animal Research, Gifu University Graduate School of Medicine, and the UCCCR Guidelines for the Welfare of Animal in Experimental Neoplasia.

Statistical analysis. The data were examined using the Student t-test, Chi-square test, and ANOVA or Kruskal-Wallis test (with appropriate post hoc analysis for multiple comparisons) to determine statistical significances. The $\mathrm{p}$-values $<0.05$ were regarded as statistically significant.

\section{Results}

In vitro experiments for the VK3-induced signal pathway. The $\mathrm{IC}_{50}(\mu \mathrm{M})$ of VK3 was calculated as $25.1 \pm 0.2,22.0 \pm 0.7$, 
A

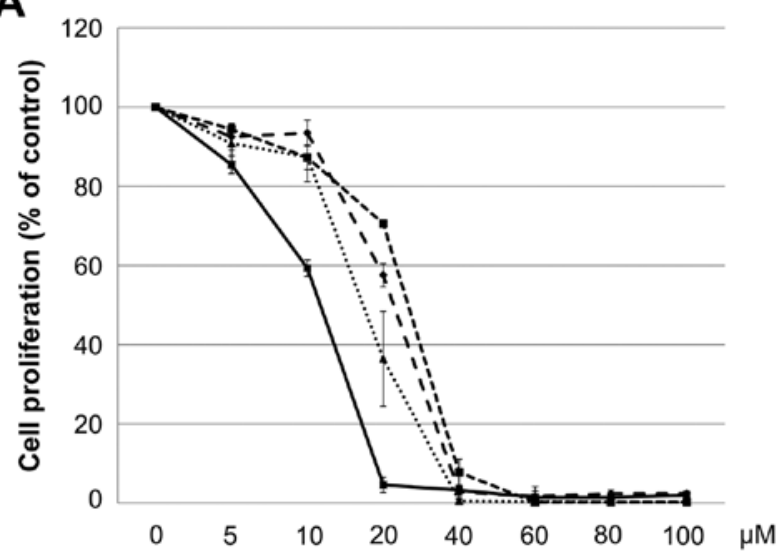

B

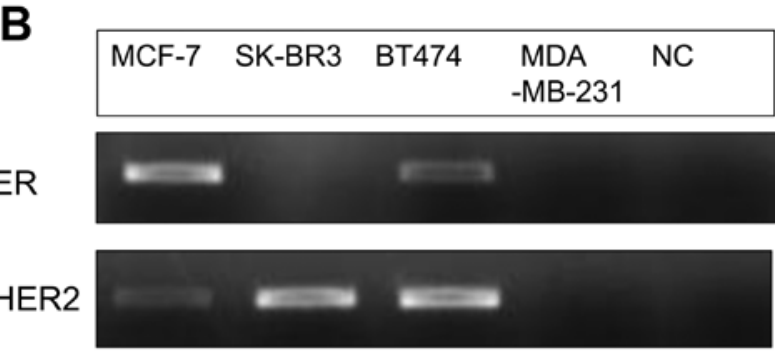

Figure 1. Subtypes of human breast cancer cells. (A) Cell proliferation (\% of control) of human breast cancer cell lines showed $\mathrm{IC}_{50} \mathrm{~s}(\mu \mathrm{M})$ of VK3 for MCF-7 (25.1), SK-BR3 (11.3), BT474 (22) and MDA-MB-231 (17). (B) PCR assay of several types of breast cancer cell lines. In the treated cell lines, MCF-7 and BT474 were found to be hormonal receptor-positive and SK-BR3 to be HER2-positive by PCR.

$11.3 \pm 0.3$ and $17.0 \pm 2.7$ on MCF7, BT474, SK-BR3 and MDA-MB-231, respectively (Fig. 1A). Of the treated cell lines, MDA-MB-231 was typed as TNBC based on PCR experiments (Fig. 1B) and protein expression by western blotting (data not shown). Then, the VK3-mediated signaling pathway on the receptors and cellular factors were examined for MDA-MB-231 (Fig. 2A). VK3 induced phosphorylation of whole tyrosine in a time-dependent manner, $1.9 \pm 0.1$-fold at $5 \mathrm{~min}, 3.5 \pm 0.2$-fold at $30 \mathrm{~min}$ and $4.2 \pm 0.3$-fold at $120 \mathrm{~min}$, compared to the control. Epidermal growth factor receptor (EGFR) was also activated 1.1-fold at $5 \mathrm{~min}$, but c-Met was not phosphorylated. Of the cell signaling factors, ERK was activated in a time-dependent manner, 3.4 \pm 0.1 -fold at $5 \mathrm{~min}$ to $4.5 \pm 0.1$-fold at $120 \mathrm{~min}$ (Fig. 2B). The phosphorylation of both JNK and mTOR peaked at 1.3 -fold at $5 \mathrm{~min}$, and Akt remained at a plateau of 1.5 -fold from 5 to $120 \mathrm{~min}$. Regarding cell cyclerelated factors, accumulation of cyclin D1 was detected at 1.2-fold the control from $12 \mathrm{~h}$ by VK3, whereas cyclin B1 was reduced by 0.65 -fold (Fig. $2 \mathrm{C}$ ). The expression of inactivated caspase- 3 was decreased 0.7 -fold, and that of the activated type of cleaved PARP was increased by 1.2 -fold at $6 \mathrm{~h}$ (Fig. 2D). As shown in Fig. 3, the activation of ERK or JNK was not affected by the EGFR inhibitor even at a concentration adequate to block EGFR phosphorylation. Next, the effects of antioxidants on VK3-induced cell signaling and growth were examined (Fig. 4). L-cysteine was found to inhibit VK3-induced ERK phosphorylation in a dose-dependent manner; especially, concentrations of $0.2 \mathrm{mM}$ or more blocked ERK phosphorylation completely, and its growth inhibitory action was also
A

\begin{tabular}{|l|llll}
\hline $20 \mu \mathrm{M}(\min )$ & 0 & 5 & 30 & 120
\end{tabular}

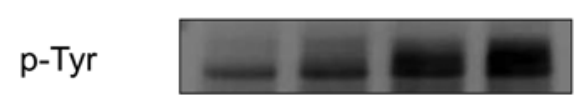

p-EGFR

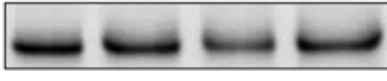

p-cMet

$\beta$-actin

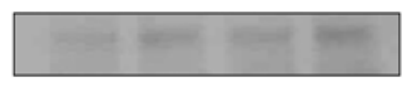

B

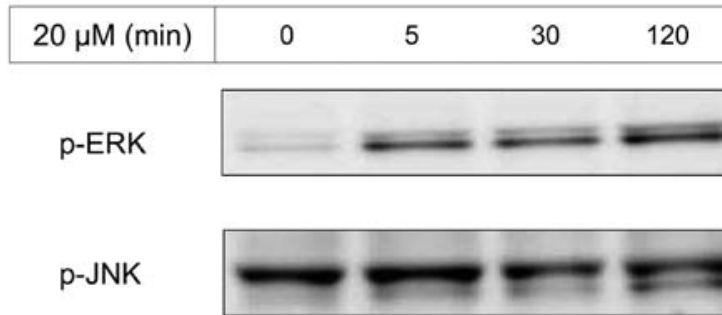

p-Akt

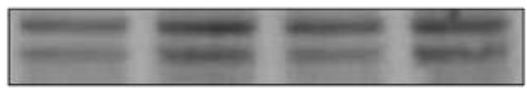

p-mTOR

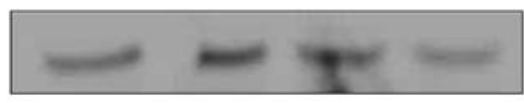

$\beta$-actin

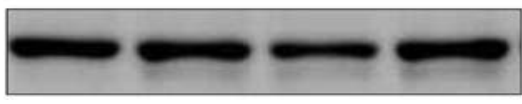

C

\begin{tabular}{|l|llll|}
\hline $10 \mu \mathrm{M}(\mathrm{h})$ & 0 & 12 & 24 & 48 \\
\hline
\end{tabular}

Cyclin D1

Cyclin B1

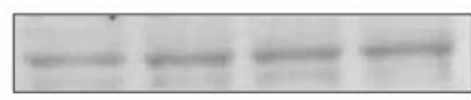

$\beta$-actin

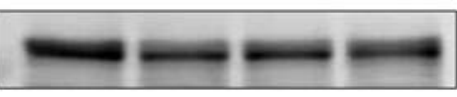

D

\begin{tabular}{l|llll|}
\hline $10 \mu \mathrm{M}(\mathrm{h})$ & 0 & 6 & 12 & 24 \\
\hline & & & \\
Caspase-3 & & & & \\
\hline
\end{tabular}

Figure 2. VK3-induced effect on MDA-MB-231 by western blotting. (A) Tyrosine, EGFR, AKT and mTOR were activated by VK3 but not by c-Met (data for AKT and mTOR not shown). (B) After administration of VK3 (concentration $20 \mu \mathrm{M}$ ), ERK was phosphorylated from $5 \mathrm{~min}$ to $>2 \mathrm{~h}$. (C) Accumulation of cyclin D1 was detected 1.2-fold the control from $12 \mathrm{~h}$ by VK3 $(10 \mu \mathrm{M})$, whereas cyclin B1 was reduced 0.65 -fold. (D) The expression of inactivated caspase- 3 was decreased by 0.7 -fold and the activated type of cleaved PARP was increased by 1.2 -fold at $6 \mathrm{~h}$. 


\begin{tabular}{|c|c|c|c|}
\hline VK3 $(20 \mu \mathrm{M})$ & - & 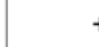 & + \\
\hline $\begin{array}{l}\text { EGFR inhibitor } \\
1.25 \mu \mathrm{M}\end{array}$ & - & & + \\
\hline$p$-EGFR & 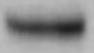 & $=$ & $=$ \\
\hline$p$-ERK & & & $=$ \\
\hline$p-J N K$ & & $=$ & 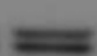 \\
\hline$\beta$-actin & 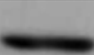 & - & 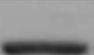 \\
\hline
\end{tabular}

Figure 3. VK3 and EGFR-inhibitor. EGFR-inhibitor inhibited EGFR activation at a concentration of $1.25 \mu \mathrm{M}$, and ERK activation at a concentration of $5 \mu \mathrm{M}$ (data not shown) despite inhibition of JNK activation at a concentration of $1.25 \mu \mathrm{M}$.

inhibited. In contrast, another antioxidant agent, catalase, showed no effect on either ERK phosphorylation or growth inhibition, and VK3 generated reactive oxygen species (ROS), as assessed by fluorescence microscopy compared with the negative control (Fig. 5).

In vivo experiments in xenograft tumors in mice. On built-up tumors under the skin of mice created by injection of $1.0 \times 10^{7}$ MDA-MB-231 cells, local treatment with VK3 was effective time- and dose-dependently (Fig. 6A). VK3 at 20 and $50 \mathrm{mM}$ decreased the tumor size to $170.8 \pm 96.1$ and $161.3 \pm 25.0$ on day 1 and $93.3 \pm 45.3$ and $81.7 \pm 34.0$ on day 3 , respectively. The experiments for total tumor volume also showed a dose-dependent effect of VK3 (Fig. 6B). At 30 min after injection of VK3, the expression of phosphorylated ERK was clearly increased 10.9-fold the control in tumor tissue, whereas ethanol itself had no effect.

\section{Discussion}

Drug therapies for breast cancer have been selected on the basis of the expression of hormonal receptors or HER2, but therapy for TNBC remains difficult because of its high potential for malignancy and its drug-resistant ability. In the present study, VK3 caused cell growth inhibition regardless of the molecular subtypes from expression of the receptors. VK3 could disrupt cellular function via two distinct chemical pathways, by generating ROS and by modifying cellular nucleophiles such as cysteine residues on proteins. According to these mechanisms, redox cycling, and arylating potential (27), the mechanisms of the cellular growth inhibitory effects of VK3 will be argued.

Mitochondria undergo an initial priming phase associated with hyperpolarization, which leads to an effector phase during apoptosis. Clinical anticancer drugs can induce cytotoxicity and the abrogation of proliferative signals though ROS production in cancer cells (29). ROS are well known to mediate mitochondrial dysfunction and apoptosis with the
A

\begin{tabular}{|c|c|c|c|c|c|}
\hline VK3 $(20 \mu \mathrm{M})$ & - & \multicolumn{4}{|c|}{+} \\
\hline L-cysteine $(\mathrm{mM})$ & 0 & 0.002 & 0.02 & 0.2 & 2 \\
\hline \multirow{2}{*}{ p-ERK } & $==\square=$ \\
\cline { 2 - 2 }
\end{tabular}

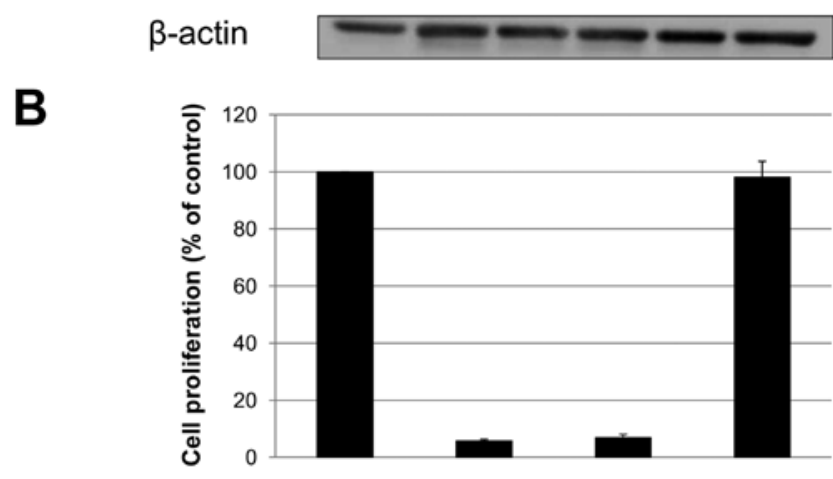

\begin{tabular}{|c|c|c|c|}
\hline VK3 $(20 \mu \mathrm{M})$ & - & \multicolumn{3}{|c|}{+} \\
\hline L-cysteine $(\mathrm{mM})$ & 0 & 0.02 & 2 \\
\hline
\end{tabular}

C

\begin{tabular}{|c|c|c|c|c|c|}
\hline VK3 $(20 \mu \mathrm{M})$ & - & \multicolumn{4}{|c|}{+} \\
\hline Catalase $(\mu \mathrm{g} / \mathrm{ml})$ & 0 & 50 & 100 & 200 & 400 \\
\hline p-ERK & \\
$\beta$-actin & \\
\hline
\end{tabular}

D

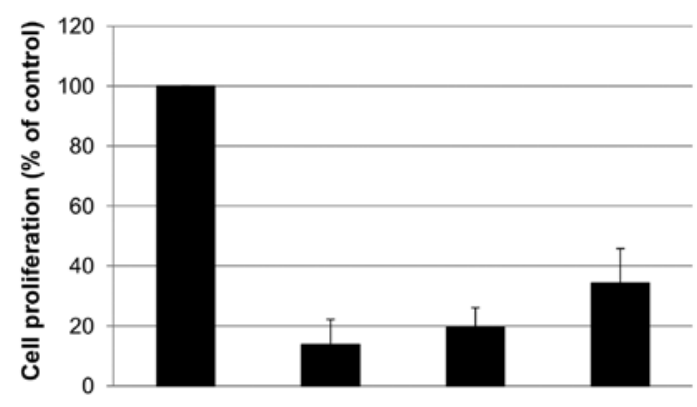

\begin{tabular}{|c|c|c|c|}
\hline VK3 $(20 \mu \mathrm{M})$ & - & + & \\
\hline Catalase $(\mu \mathrm{g} / \mathrm{ml})$ & 0 & 100 & 1000 \\
\hline
\end{tabular}

Figure 4. ERK and JNK inhibition and cell proliferation of VK3 and antioxidant. (A and B) L-cysteine inhibited both ERK and JNK activation (A). $\mathrm{L}$-cysteine rescued cell death at a concentration of $2 \mathrm{mM}$ when combined with VK3 (B). (C and D) Catalase suppressed the activation of JNK but did not inhibit the activation of ERK (C). Catalase did not rescue cell death in spite of the high concentration compared to L-cysteine (D).

activation of caspase-3 (30), despite the loss of mitochondrial membrane potential (31). Indeed, activation of caspase-3 was detected in VK3-treated glioblastoma cells with ROS produc- 


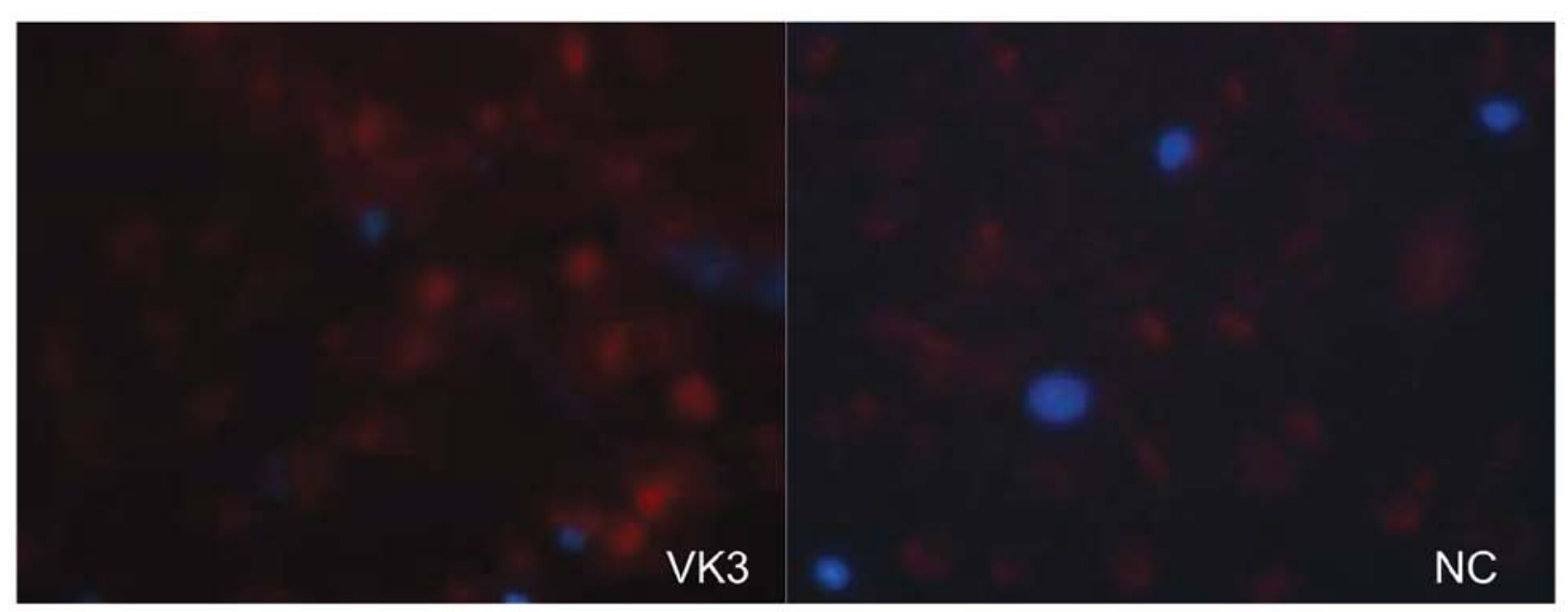

Figure 5. ROS detection. VK3 was capable of ROS generation (red) as shown by fluorescence microscopy.

A

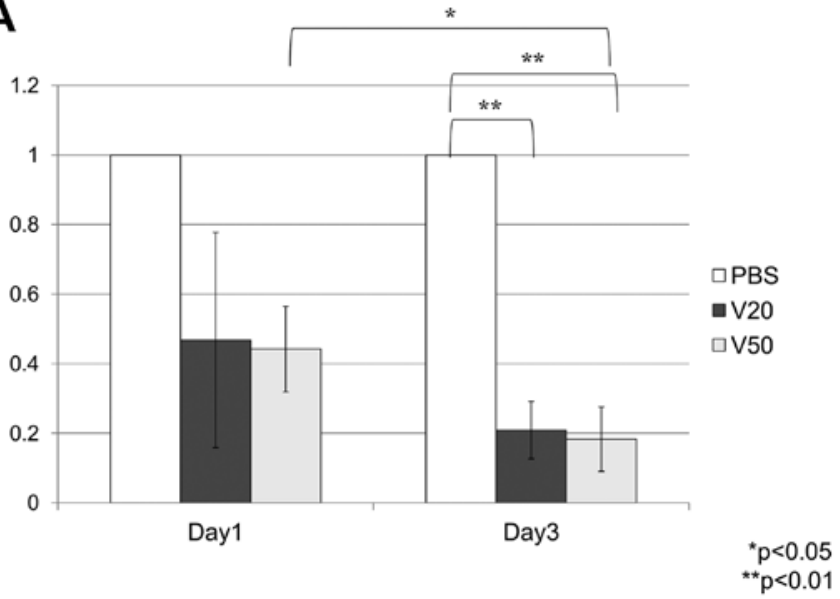

B

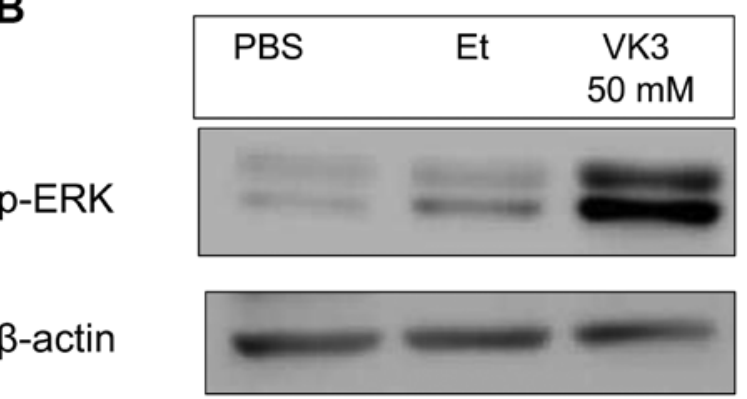

Figure 6. Local treatment with VK3 in vivo. (A) In comparison with PBS, VK3 reduced subcutaneous tumor volume on days 1 and $3\left({ }^{*} \mathrm{p}<0.05,{ }^{* *} \mathrm{p}<0.01\right)$. (B) Western blotting of the subcutaneous tumor shows growth of p-ERK in the tumor with local injection of VK3.

tion (32). Mitochondrial damage through ROS production not only induces apoptosis, but it also reduces cell survival factors (33). Of them, survivin is highly expressed in a variety human cancer cells but not in normal cells. Because its high level correlates with more aggressive behavior, decreased response to chemotherapeutic agents and shortened survival time (34), the blockage of survivin provides an important strategy for cancer therapy. Poly (ADP-ribose) polymerase (PARP) is also one of the DNA repair proteins that has been shown to be cleaved when cells undergo apoptosis. ROS production was demonstrated to lead to both survivin inhibition and PARP protein cleavage (33). The mitochondria-related action is a main path for cell death (35), indicating that ROS generation plays one of the critical roles in the VK3-induced cellular effect (36). The present study showed that VK3 activated the apoptotic pathway through caspase-3 or PARP cleavage and arrested the cell cycle (Fig. 2). VK3 was also reported to lead not only to the generation of ROS but also to growth inhibition with the phosphorylation of ERK $(25,26)$. The agent, and ROS, that provokes the sustained activation of ERK can induce the progressive accumulation of death-promoting factors. Sustained cytoplasmic ERK activity might promote senescence or autophagy, whereas sustained nuclear sequestration of ERK activity might trigger apoptosis (37). From the evidence that prolonged ERK activation promotes death of human cancer cell lines (38), the relationship of ERK to cell growth inhibition was indicated to support the present results.

Protein tyrosine phosphorylation is regulated by a balance between the action of protein tyrosine phosphatase (PTPase) and protein tyrosine kinase (PTK) activities. Ligand-induced phosphorylation usually leads to PTK activity, whereas inhibition of PTPase also induces phosphorylation of cellular signal protein due to binding at the active site of PTPase (39). According to a previous report (25), VK3 activates the signaling pathway by inhibition of PTPase in hepatoma cells without causing any ligand stimulation, and MAPKs are commonly activated by the upstream action including the receptor. However, the present study demonstrated that ERK and JNK were phosphorylated even under the blocked condition of the receptor by its inhibitor. Taken together, the phosphorylation of MAPKs might be mediated by a direct effect on their PTPase activity. VK3 was also detected to lead to MAPKs phosphorylation by a dual system with or without the receptor signaling pattern. From the experiments with antioxidant agents, VK3-mediated ERK phosphorylation was completely inhibited by the thiol antioxidant L-cysteine but not by the non-thiol agent catalase (Fig. 4), indicating that the mechanism of sulfhydryl arylation (40) is critical. The growth inhibitory action of VK3 was also antagonized completely by the thiol antioxidant. Of the cellular signaling factors, ERK is 
usually recognized to relate to cell proliferation (39), whereas ERK phosphorylation was shown to promote apoptosis or cell cycle arrest and lead to growth inhibition $(26,41)$. In contrast, ERK phosphorylation also focuses on ROS-independent DNA damage that leads to the inhibition of breast cancer cell growth $(29,37)$. Actually, in melanoma cells, inhibiting the appearance of a ubiquitin, which is required for protein ubiquitination related to a key biological event, appeared to arrest tumorigenesis through ERK phosphorylation (42). A more recent study (43) showed some keratins, which are a major component of the cellular cytoskeletal structure, to have a dependent role with ERK, and blockage of their activation was found to delay the onset of VK3-induced growth inhibition. Furthermore, because of their effect on promoting cell growth, cancer cells are well known to include greatly more ERK protein than normal cells (44). Thus, VK3 might be more effective against vigorous cell growth, indicating that VK3 might have an expected therapeutic potential even for TNBC. To reduce the harmful toxicity of VK3 by considering the drug delivery system, a VK3 analog compound has been developed for breast cancer therapy on mice in an in vivo experiment (33). In parallel with these novel trials, with the aim to improve the problems of VK3 toxicity systemically, the present novel concept of VK3 as a local treatment against TNBC may be accepted clinically as a favorable treatment modality in the near future.

\section{References}

1. Jemal A, Bray F, Center MM, Ferlay J, Ward E and Forman D Global cancer statistics. CA Cancer J Clin 61: 69-90, 2011.

2. Williams C and Lin CY: Oestrogen receptors in breast cancer: Basic mechanisms and clinical implications. E Cancer Medical Sci 7: 370, 2013

3. Oostra DR and Macrae ER: Role of trastuzumab emtansine in the treatment of HER2-positive breast cancer. Breast Cancer (Dove Med Press) 6: 103-113, 2014.

4. Zelnak AB and Wisinski KB: Management of patients with HER2-positive metastatic breast cancer: Is there an optimal sequence of HER2-directed approaches? Cancer 121: 17-24, 2015.

5. Abramson VG, Lehmann BD, Ballinger TJ and Pietenpol JA: Subtyping of triple-negative breast cancer: Implications for therapy. Cancer 121: 8-16, 2015.

6. O'Toole SA, Beith JM, Millar EK, West R, McLean A, Cazet A, Swarbrick A and Oakes SR: Therapeutic targets in triple negative breast cancer. J Clin Pathol 66: 530-542, 2013.

7. Dent R, Trudeau M, Pritchard KI, Hanna WM, Kahn HK, Sawka CA, Lickley LA, Rawlinson E, Sun P and Narod SA: Triple-negative breast cancer: Clinical features and patterns of recurrence. Clin Cancer Res 13: 4429-4434, 2007.

8. Liedtke C, Mazouni C, Hess KR, André F, Tordai A, Mejia JA, Symmans WF, Gonzalez-Angulo AM, Hennessy B, Green M, et al: Response to neoadjuvant therapy and long-term survival in patients with triple-negative breast cancer. J Clin Oncol 26: 1275-1281, 2008.

9. Lehmann BD, Bauer JA, Chen X, Sanders ME, Chakravarthy AB, Shyr Y and Pietenpol JA: Identification of human triple-negative breast cancer subtypes and preclinical models for selection of targeted therapies. J Clin Invest 121: 2750-2767, 2011.

10. Tsimberidou AM, Iskander NG, Hong DS, Wheler JJ, Falchook GS, Fu S, Piha-Paul S, Naing A, Janku F, Luthra R, et al: Personalized medicine in a phase I clinical trials program: The MD Anderson Cancer Center initiative. Clin Cancer Res 18: 6373-6383, 2012.

11. Gelmon K, Dent R, Mackey JR, Laing K, McLeod D and Verma S: Targeting triple-negative breast cancer: Optimising therapeutic outcomes. Ann Oncol 23: 2223-2234, 2012.

12. Nguyen T, Hattery E and Khatri VP: Radiofrequency ablation and breast cancer: A review. Gland Surg 3: 128-135, 2014.
13. Hamza A and Elrefaey S: Non-surgical treatment of early breast cancer: Techniques on the way. Gland Surg 3: 149-150, 2014.

14. Manenti G, Scarano AL, Pistolese CA, Perretta T, Bonanno E, Orlandi A and Simonetti G: Subclinical breast cancer: Minimally invasive approaches. Our experience with percutaneous radiofrequency ablation vs. cryotherapy. Breast Care (Basel) 8: 356-360, 2013.

15. Zagar TM, Vujaskovic Z, Formenti S, Rugo H, Muggia F, O'Connor B, Myerson R, Stauffer P, Hsu I-C, Diederich C, et al: Two phase I dose-escalation/pharmacokinetics studies of low temperature liposomal doxorubicin (LTLD) and mild local hyperthermia in heavily pretreated patients with local regionally recurrent breast cancer. Int J Hyperthermia 30: 285-294, 2014.

16. Kovacic P and Jacintho JD: Mechanisms of carcinogenesis: Focus on oxidative stress and electron transfer. Curr Med Chem 8: 773-796, 2001

17. Dong-Yun S, Yu-Ru D, Shan-Lin L, Ya-Dong Z and Lian W: Redox stress regulates cell proliferation and apoptosis of human hepatoma through Akt protein phosphorylation. FEBS Lett 542: 60-64, 2003.

18. Suresh S, Raghu D and Karunagaran D: Menadione (Vitamin K3) induces apoptosis of human oral cancer cells and reduces their metastatic potential by modulating the expression of epithelial to mesenchymal transition markers and inhibiting migration. Asian Pac J Cancer Prev 14: 5461-5465, 2013.

19. Baran I, Ionescu D, Filippi A, Mocanu MM, Iftime A, Babes R, Tofolean IT, Irimia R, Goicea A, Popescu V, et al: Novel insights into the antiproliferative effects and synergism of quercetin and menadione in human leukemia Jurkat T cells. Leuk Res 38: 836-849, 2014.

20. Margolin KA, Akman SA, Leong LA, Morgan RJ, Somlo G, Raschko JW, Ahn C and Doroshow JH: Phase I study of mitomycin $\mathrm{C}$ and menadione in advanced solid tumors. Cancer Chemother Pharmacol 36: 293-298, 1995.

21. Tetef M, Margolin K, Ahn C, Akman S, Chow W, Leong L, Morgan RJ Jr, Raschko J, Somlo G and Doroshow JH: Mitomycin C and menadione for the treatment of lung cancer: A phase II trial. Invest New Drugs 13: 157-162, 1995.

22. Tetef M, Margolin K, Ahn C, Akman S, Chow W, Coluzzi P, Leong L, Morgan RJ Jr, Raschko J, Shibata S, et al: Mitomycin C and menadione for the treatment of advanced gastrointestinal cancers: A phase II trial. J Cancer Res Clin Oncol 121: 103-106, 1995.

23. Osada S, Tomita H, Tanaka Y, Tokuyama Y, Tanaka H, Sakashita F and Takahashi T: The utility of vitamin K3 (menadione) against pancreatic cancer. Anticancer Res 28A: 45-50, 2008.

24. Osada S, Sakashita F, Hosono Y, Nonaka K, Tokuyama Y, Tanaka H, Sasaki Y, Tomita H, Komori S, Matsui S, et al: Extracellular signal-regulated kinase phosphorylation due to menadione-induced arylation mediates growth inhibition of pancreas cancer cells. Cancer Chemother Pharmacol 62: 315-320, 2008.

25. Osada S and Carr BI: Mechanism of novel vitamin K analog induced growth inhibition in human hepatoma cell line. J Hepatol 34: 676-682, 2001

26. Osada S, Saji S and Osada K: Critical role of extracellular signalregulated kinase phosphorylation on menadione (vitamin K3) induced growth inhibition. Cancer 91: 1156-1165, 2001.

27. Osada S, Osada K and Carr BI: Tumor cell growth inhibition and extracellular signal-regulated kinase (ERK) phosphorylation by novel K vitamins. J Mol Biol 314: 765-772, 2001.

28. Imai H, Saio M, Nonaka K, Suwa T, Umemura N, Ouyang GF, Nakagawa J, Tomita H, Osada S, Sugiyama Y, et al: Depletion of $\mathrm{CD} 4{ }^{+} \mathrm{CD} 25^{+}$regulatory $\mathrm{T}$ cells enhances interleukin-2-induced antitumor immunity in a mouse model of colon adenocarcinoma. Cancer Sci 98: 416-423, 2007.

29. Wang S, Konorev EA, Kotamraju S, Joseph J, Kalivendi S and Kalyanaraman B: Doxorubicin induces apoptosis in normal and tumor cells via distinctly different mechanisms. intermediacy of H (2) O (2)- and p53-dependent pathways. J Biol Chem 279: 25535-25543, 2004.

30. Mizutani H, Tada-Oikawa S, Hiraku Y, Oikawa S, Kojima M and Kawanishi S: Mechanism of apoptosis induced by a new topoisomerase inhibitor through the generation of hydrogen peroxide. J Biol Chem 277: 30684-30689, 2002.

31. Chen FH, Zhang LB, Qiang L, Yang Z, Wu T, Zou MJ, Tao L, You QD, Li ZY, Yang Y, et al: Reactive oxygen species-mitochondria pathway involved in LYG-202-induced apoptosis in human hepatocellular carcinoma HepG (2) cells. Cancer Lett 296: 96-105, 2010. 
32. Wu J, Chien CC, Yang LY, Huang GC, Cheng MC, Lin CT, Shen SC and Chen YC: Vitamin K3-2, 3-epoxide induction of apoptosis with activation of ROS-dependent ERK and JNK protein phosphorylation in human glioma cells. Chem Biol Interact 193: 3-11, 2011.

33. Yang CR, Liao WS, Wu YH, Murugan $\mathrm{K}$, Chen $\mathrm{C}$ and Chao JI: CR108, a novel vitamin K3 derivative induces apoptosis and breast tumor inhibition by reactive oxygen species and mitochondrial dysfunction. Toxicol Appl Pharmacol 273: 611-622, 2013.

34. Johnson ME and Howerth EW: Survivin: A bifunctional inhibitor of apoptosis protein. Vet Pathol 41: 599-607, 2004.

35. Akiyoshi T, Matzno S, Sakai M, Okamura N and Matsuyama K: The potential of vitamin K3 as an anticancer agent against breast cancer that acts via the mitochondria-related apoptotic pathway. Cancer Chemother Pharmacol 65: 143-150, 2009.

36. Sasaki R, Suzuki Y, Yonezawa Y, Ota Y, Okamoto Y, Demizu Y, Huang P, Yoshida H, Sugimura K and Mizushina Y: DNA polymerase gamma inhibition by vitamin K3 induces mitochondria-mediated cytotoxicity in human cancer cells. Cancer Sci 99: 1040-1048, 2008.

37. Li X, Wang K, Ren Y, Zhang L, Tang XJ, Zhang HM, Zhao CQ, Liu PJ, Zhang JM and He JJ: MAPK signaling mediates sinomenine hydrochloride-induced human breast cancer cell death via both reactive oxygen species-dependent and -independent pathways: An in vitro and in vivo study. Cell Death Dis 5: e1356, 2014.
38. Cagnol S and Chambard JC: ERK and cell death: Mechanisms of ERK-induced cell death - apoptosis, autophagy and senescence. FEBS J 277: 2-21, 2010.

39. Osada S and Yoshida K: A novel strategy for advanced pancreatic cancer - progression of molecular targeting therapy. Anticancer Agents Med Chem 9: 877-881, 2009.

40. Osada S and Saji S: New approach to cancer therapy: The application of signal transduction to anti-cancer drug. Curr Med Chem Anticancer Agents 3: 119-131, 2003.

41. Esakky P, Hansen DA, Drury AM and Moley KH: Cigarette smoke-induced cell cycle arrest in spermatocytes [GC-2spd (ts)] is mediated through crosstalk between Ahr-Nrf2 pathway and MAPK signaling. J Mol Cell Biol 7: 73-87, 2015.

42. Shah M, Stebbins JL, Dewing A, Qi J, Pellecchia M and Ronai ZA: Inhibition of Siah2 ubiquitin ligase by vitamin K3 (menadione) attenuates hypoxia and MAPK signaling and blocks melanoma tumorigenesis. Pigment Cell Melanoma Res 22: 799-808, 2009.

43. Scott GK, Atsriku C, Kaminker P, Held J, Gibson B, Baldwin MA and Benz CC: Vitamin K3 (menadione)-induced oncosis associated with keratin 8 phosphorylation and histone $\mathrm{H} 3$ arylation. Mol Pharmacol 68: 606-615, 2005.

44. Osada S, Kanematsu M, Imai H, Goshima S and Sugiyama Y: Evaluation of extracellular signal regulated kinase expression and its relation to treatment of hepatocellular carcinoma. J Am Coll Surg 201: 405-411, 2005. 